\title{
A Case of a Rapidly Growing Granulocyte Colony-Stimulating Factor-Producing Squamous Cell Carcinoma of the Breast
}

\author{
Haruna Noda ${ }^{a}$ Michiko Yamashita ${ }^{a}$ Akari Murakami ${ }^{a}$ Kumiko Okujima ${ }^{a}$ \\ Kana Takemoto ${ }^{a}$ Megumi Takaoka $^{a}$ Erina Kusakabe ${ }^{a}$ Reina Aoki ${ }^{a}$ \\ Kana Taguchi $^{a}$ Kanako Nishiyama ${ }^{a}$ Riko Kitazawa $^{\mathrm{b}}$ Yoshiaki Kamei ${ }^{\mathrm{a}}$ \\ Yasutsugu Takadac \\ aBreast Center, Ehime University Hospital, Toon, Japan; ${ }^{b}$ Department of Molecular \\ Pathology, Ehime University Graduate School of Medicine, Toon, Japan; 'Department of \\ Hepato-Biliary-Pancreatic Surgery and Breast Surgery, Ehime University Graduate School of \\ Medicine, Toon, Japan
}

\section{Keywords}

Granulocyte colony-stimulating factor-producing cancer - Breast cancer - Adriamycin .

Paclitaxel

\section{Abstract}

A 34-year-old woman with a rapidly growing right breast mass visited our hospital. The mass was diagnosed as a right breast cancer (CT3N1M0 stage IIIA). Her serum leucocyte count and $\mathrm{C}$-reactive protein levels were high, and she had persistent fever. However, serum procalcitonin and $\beta$-D-glucan levels were normal, and no apparent infection focus was detected, although her serum granulocyte colony-stimulating factor (G-CSF) level was markedly elevated to $42.7 \mathrm{pg} / \mathrm{mL}$. Therefore, a G-CSF-producing breast cancer was suspected. A pathological analysis of the surgical specimen revealed a squamous cell carcinoma of the breast (pT2N0 [i+] M0 stage $\| \mathrm{A}$ ). Right mastectomy (with the resection of the pectoralis major muscle), axillary lymph node dissection, and split layer grafting were performed. The leucocyte count and serum G-CSF level decreased on postoperative day (POD) 1 and normalized on POD 6. As adjuvant chemotherapy, 4 cycles of a combination chemotherapy with adriamycin and cyclophosphamide and 12 cycles of weekly paclitaxel were administered. After chemotherapy, the patient also underwent postmastectomy radiotherapy. Currently, 30 months after surgery, the patient is alive and well with neither progression nor distant metastasis. G-CSF-producing breast cancers tend to rapidly grow such as in the current case; thus, surgery should be performed immediately, followed by appropriate adjuvant treatment. 


\section{Introduction}

Granulocyte colony-stimulating factor (G-CSF)-producing breast cancer is an extremely rare variant of breast cancer and, to the best of our knowledge, only 13 cases have been reported, including this case [1-12]. It is known to cause a marked increase in white blood cell (WBC) count without signs of an infection. G-CSF-producing breast cancer has a very poor prognosis, and no effective drug therapy has been established. Herein, we report a case of G-CSF-producing breast cancer. A multimodal treatment, including surgery, chemotherapy, and radiation, was implemented for the patient, and she is currently alive and recurrence free 30 months after surgery.

\section{Case Report/Case Presentation}

\section{Chief Complaint}

A 34-year-old woman with a rapidly growing right breast mass presented to our hospital.

\section{Medical History}

Four months before her hospital visit, a breast cancer screening using ultrasound showed no abnormalities; however, she noted a right breast mass 3 weeks after the screening. The mass rapidly increased in size, and she developed back pain and high fever. Thus, she visited our department 4 months after the breast cancer screening.

Familial and Past Medical History

Familial and past medical history was nonsignificant.

\section{Physical Exam Findings}

A hard mass measuring $6 \mathrm{~cm}$ in size was noted on palpation. Skin redness and tenderness in the upper inner quadrant of her right breast were also observed. She also reported pain at the site of the mass when the upper limbs were mobilized. No palpable lymph node or papilla secretion was observed.

\section{Laboratory Findings}

Blood test at the first visit indicated inflammation (WBC count, 10,400/mL [normal range, 3.5-9.1 $\times 10^{3} / \mu \mathrm{L}$; C-reactive protein levels were $8.20 \mathrm{mg} / \mathrm{dL}$ [normal range, $\leq 0.20$ $\mathrm{mg} / \mathrm{dL}]$ ). WBC count increased to $14,600 / \mathrm{mL}$ before the start of treatment. However, procalcitonin and $\beta$-D-glucan results were normal. Thus, we considered that there was no active infectious disease. However, we strongly suspected a G-CSF-producing tumor based on high serum interleukin $6(16 \mathrm{pg} / \mathrm{mL}$ [normal range, $<8 \mathrm{pg} / \mathrm{mL}])$ and serum G-CSF $(42.7 \mathrm{pg} / \mathrm{mL}$ [normal range, $<39.0 \mathrm{pg} / \mathrm{mL}$ ]) levels (EIA, BML, Inc., Japan).

\section{Mammography}

A mammography was difficult to perform because of the patient's severe pain; however, focal asymmetric density was observed in the upper part of the right breast.

\section{Ultrasonography}

A hypoechoic mass with a well-defined coarse-looking ellipse was observed on the cephalad side of the right breast, part of which showed no internal echo or necrosis, and internal bleeding was suspected. The dorsal boundary of the mass was partly ruptured, and abundant internal blood flow was noted. 
Noda et al.: A Rapidly Growing Granulocyte Colony-Stimulating Factor-Producing Breast Cancer

\section{Breast Magnetic Resonance Imaging}

A 4-cm-sized mass was found in the right upper medial region, and its contrast pattern was a rapid washout. There was a contrast deficit in the internal part of the mass, and cystic degeneration was considered. The tumor was in contact with the pectoralis major muscle, and pectoralis major muscle invasion was suspected.

\section{Fluorodeoxyglucose Positron Emission Tomography-Computed Tomography}

A 37-mm-sized mass with high fluorodeoxyglucose (FDG) concentration (maximum standardized uptake value $=22.1$ ) was found in the upper medial region of the right breast. FDG accumulation was also noted in the axillary lymph node, and axillary lymph node metastasis was suspected. No distinct findings indicated distant metastasis. Diffuse FDG accumulation was noted on a whole-body bone scan (shown in Fig. 1).

\section{Vacuum-Assisted Needle Biopsy}

Although there was no distinct keratinization, some cancer cells were arranged in a cobblestone shape, and an image with suspected intercellular bridges and individual cell keratinization was observed. Squamous epithelial marker p40 was partially positive, and squamous metaplasia occurred. Estrogen and progesterone receptors were negative, human epidermal growth factor receptor 2 was negative, and the Ki-67 protein labeling index was over $90 \%$.

\section{Diagnosis and Treatment}

The patient was finally diagnosed with right breast cancer cT3N1M0 stage IIIA (Union for International Cancer Control [UICC] 8th edition). In addition to sustained fever and back pain, the possibility of a G-CSF-producing breast cancer was considered owing to the elevated leucocyte count and serum G-CSF level and diffuse FDG accumulation on the whole-body bone scan. Total mastectomy was immediately performed owing to the rapid tumor growth.

\section{Surgical Procedures}

On the 16th day after the first visit to the hospital, right mastectomy (with the resection of the pectoralis major muscle), axillary lymph node dissection, and split layer grafting were performed.

\section{Pathological Diagnosis}

The tumor cells had wide acidic eosinophils, and a portion contained intercellular bridges. The squamous epithelial marker $\mathrm{p} 40$ was positive at the same site, and the cytoplasm of some tumor cells stained positively for G-CSF (shown in Fig. 2). The ratio of the tumor cells positively stained for G-CSF in the total tumor cells was approximately $65 \%$. In the marginal sinus of the largest axillary lymph node, small cancer cell masses measuring $0.1 \mathrm{~mm}$ in size corresponding to free tumor cells were found. There was no metastasis in other lymph nodes. The final diagnosis was a G-CSF-producing squamous cell carcinoma.

\section{Postoperative Course}

Decreases in WBC count $(9,800 / \mathrm{mL})$ and serum G-CSF $(27.8 \mathrm{pg} / \mathrm{mL})$ level were observed on the first day after surgery. On the sixth postoperative day, both levels decreased to within the normal range $(7,500 / \mathrm{mL}$ and $0 \mathrm{pg} / \mathrm{mL}$, respectively), and on the 26th postoperative day, the WBC count further decreased to $5,000 / \mathrm{mL}$. As an adjuvant treatment, 4 courses of adriamycin $\left(60 \mathrm{mg} / \mathrm{m}^{2}\right)$ and cyclophosphamide $\left(600 \mathrm{mg} / \mathrm{m}^{2}\right)$ chemotherapy, 12 courses of weekly paclitaxel $\left(80 \mathrm{mg} / \mathrm{m}^{2}\right)$ therapy, and postmastectomy radiotherapy ( $50 \mathrm{~Gy} / 25 \mathrm{Fr}$ ) were administered. The patient is currently alive without relapse at 30 months postoperative.

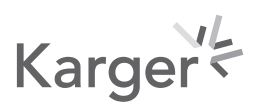


Fig. 1. Positron emission tomography-computed tomography image. Diffuse FDG is confirmed in a whole-body bone scan. FDG, fluorodeoxyglucose.

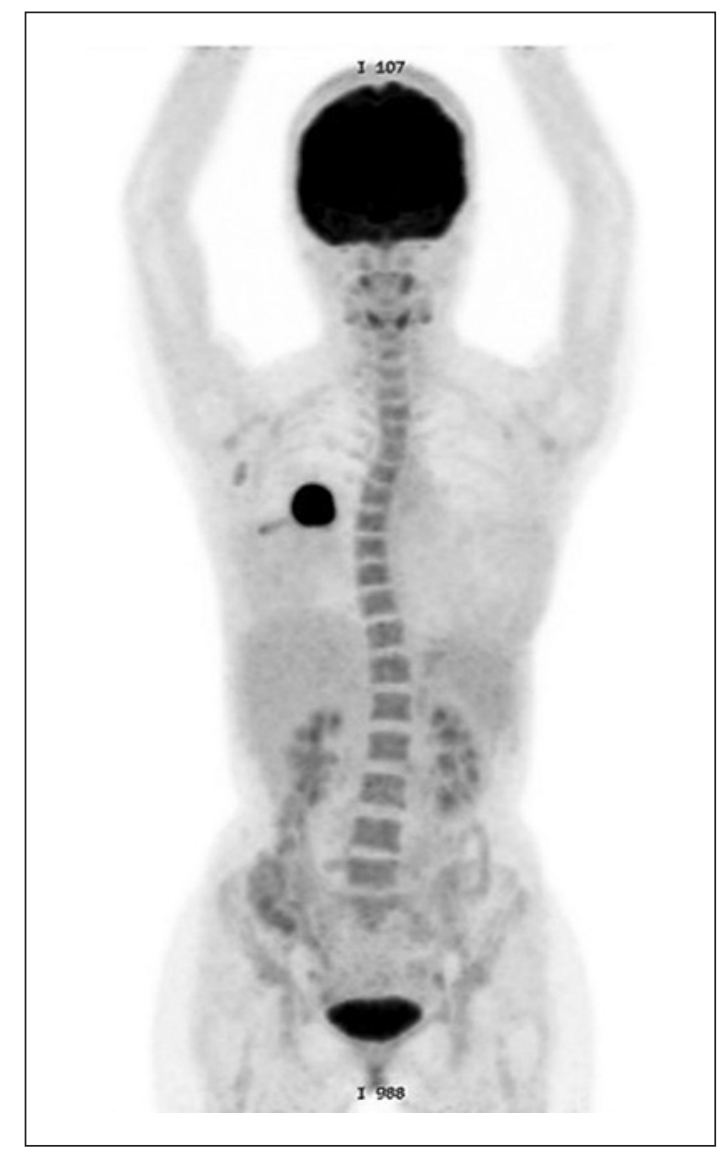

Fig. 2. Pathological findings (immunohistochemical staining of G-CSF, objective magnification, $\times 20$ ). The cytoplasm of some tumor cells is stained positively for G-CSF. G-CSF, granulocyte colony-stimulating factor.

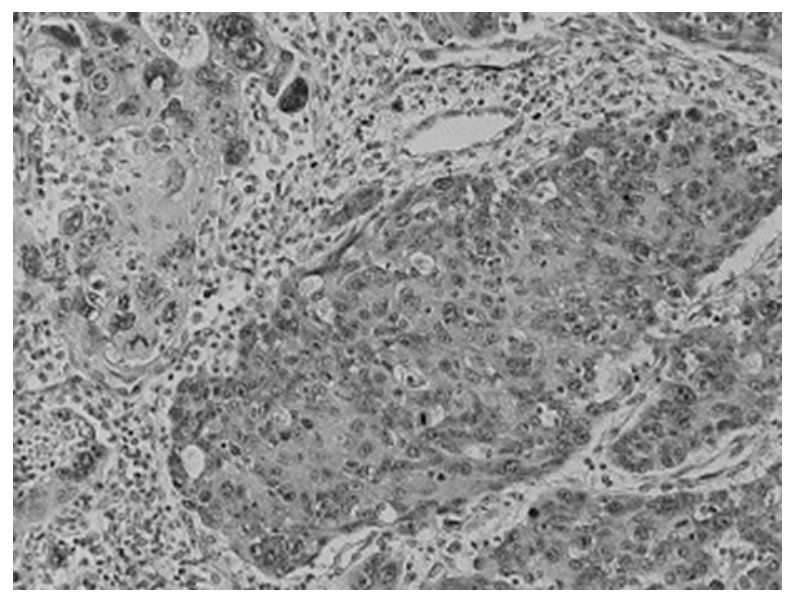

\section{Discussion/Conclusion}

G-CSF-producing tumors were first reported by Asano et al. [13] in 1977. The diagnostic criteria are as follows: (1) significant increase in WBC counts, (2) high serum G-CSF levels, (3) reduction in WBC counts via tumor resection, and (4) proof of intratumoral G-CSF production. Our current case was diagnosed as a G-CSF-producing breast cancer because it met all the above 4 criteria. To the best of our knowledge, there are only 13 reported cases of G-CSF-producing 


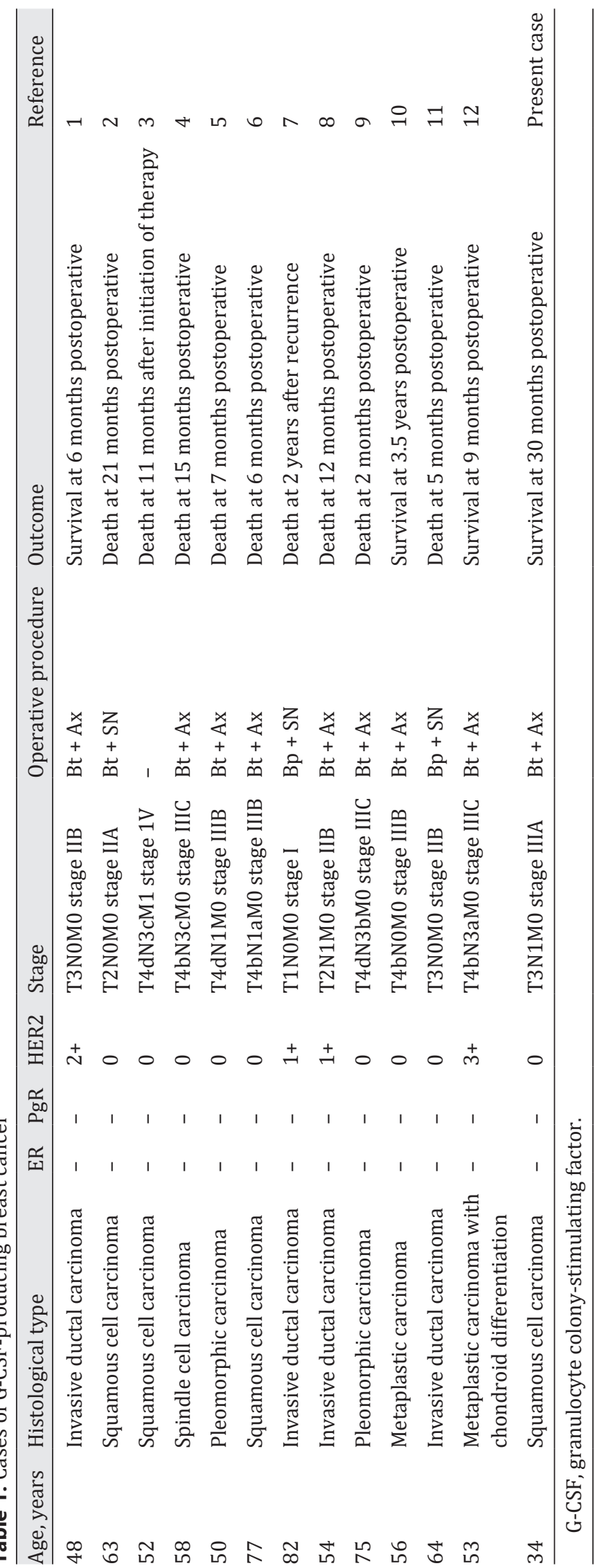

\section{Karger'}


breast cancer, including our case [1-12] (Table 1). Such tumors have a large proportion of special tissue type, and squamous cell carcinoma is a frequent type. All reported cases, except one, were advanced $\mathrm{T} 2$ or higher, and the frequent subtype was triple negative. This case also was squamous cell carcinoma and advanced T3, and the subtype was triple negative.

There are almost no reports describing the time period between symptom awareness or the date of first visit and surgery. However, 2 of the 3 cases in which the time between awareness of symptoms and surgery was $>1$ year, the patients died at 15 and 7 months after surgery, respectively (Table 1) $[4,5,12]$. The present case and another reported case underwent surgery at 4 months after symptom awareness ( 1 month from the first visit), and the patients survived 30 and 6 months postoperatively without recurrence, respectively [1]. This suggests that early therapeutic intervention may be important, but the number of cases is small, and further study is needed for better confirmation.

G-CSF-producing tumors are considered to have a poor prognosis. Almost all reported cases were treated with chemotherapy, but many of them developed metastasis or exacerbation within 3 months to 1 year, and almost all patients died within 2 years [1-12]. As early diagnosis and treatment are important, clinicians should consider G-CSF-producing tumors in patients presenting with persistent fever and back pain without indications of infection. Bone metastases should also be considered. The measurement of serum G-CSF level (EIA, BML, Inc., Japan) and G-CSF immunostaining by a pathological examination are crucial for differential diagnosis. G-CSF-producing breast cancers tend to rapidly grow such as in the current case [1-12]; thus, surgery should be performed immediately followed by appropriate adjuvant treatment.

\section{Statement of Ethics}

The article describes a case report. Therefore, no additional permission from our ethics committee was required. Written informed consent was obtained from the patient for publication of this case report and any accompanying images.

\section{Conflict of Interest Statement}

The authors have no conflicts of interest to declare.

\section{Funding Sources}

No funding sources to declare.

\section{Author Contributions}

Haruna Noda and Yoshiaki Kamei were involved in conception and design. All authors were involved in manuscript writing and gave final approval of the manuscript.

\section{Data Availability Statement}

All data generated or analyzed during this study are included in this article. Further enquiries can be directed to the corresponding author. 


\section{Case Reports in Oncology}

\begin{tabular}{l|l}
\hline Case Rep Oncol 2021;14:1175-1181 \\
\hline DOI: 10.1159/000518244 & $\begin{array}{l}\text { ○ 2021 The Author(s). Published by S. Karger AG, Basel } \\
\text { www.karger.com/cro }\end{array}$ \\
\hline
\end{tabular}

Noda et al.: A Rapidly Growing Granulocyte Colony-Stimulating Factor-Producing Breast Cancer

\section{References}

1 Kita Y, Kijima Y, Yoshinaka H, Funasako Y, Owaki T, Aikou T. A case of granulocyte-colony stimulating factor producing invasive ductal carcinoma of breast. J Jpn Surg Assoc. 2006;67:33-6.

2 Imawari Y, Kamio M, Nogi H, Kawase K, Toriumi Y, Uchida K, et al. A case of granulocyte-colony stimulating factor producing metastatic breast cancer. J Jpn Surg Assoc. 2011;72(10):2512-5.

3 Tanabe T, Ishihara N, Musha N, KuwabaraA, Tsubono T, Sakai Y. A case of mixed-type squamous cell carcinoma of the breast, suspected of being a G-CSF-producing tumor. Jpn J Breast Cancer. 2013;28:605-11.

4 Suzuki K, Ota D, Nishi T, Mori M, Kato T, Takeuchi M, et al. A case of granulocyte-colony stimulating factorproducing spindle cell carcinoma of the breast. Clin Breast Cancer. 2015;15(4):e213-7.

5 Sano N, Horiguchi S, Yamada R, Hosoi A, Idera N, Yamashita T, et al. A case of G-CSF-producing pleomorphic carcinoma of the breast. Jpn J Diagn Pathol. 2016;33:61-5.

6 Hayashi K, Oyama K, Yamada S, Kato Y, Nomoto K, Takase M, et al. A case of squamous cell carcinoma of the breast producing granulocyte-colony stimulating factor. Jpn J Breast Cancer. 2016;31:511-7.

7 Yamaguchi T, Hayashi M, Komatsu N, Hashimoto S, Koyama M. A case of granulocyte-colony stimulating factor producing breast cancer. Hok J Surg. 2016;35:43-5.

8 Inoue T, Minohata J, Tanaka M, Tabuchi T, Morimoto H, Tatsumi Y, et al. A case of granulocyte-colony stimulating factor producing breast cancer that caused rapid progression. Jpn J Cancer Chemother. 2017;44:1257-9.

9 Ogawa A, Oda G, Yasukawa T, Kumaki Y, Takiguchi N, Suzuki K, et al. A case of rapidly advancing G-CSF producing pleomorphic carcinoma of the breast appearing as an inflammatory breast cancer. Jpn J Cancer Chemother. 2017;44:1760-2.

10 Fukui Y, Kawashima M, Kawaguchi K, Takeuchi M, Hirata M, Kataoka TR, et al. Granulocyte-colony-stimulating factor-producing metaplastic carcinoma of the breast with significant elevation of serum interleukin-17 and vascular endothelial growth factor levels. Int Cancer Conf J. 2018;7:107-13.

11 Otsubo K, Tamura H, Aoki M, Kojima M. A case of rapidly progressive granulocyte-colony stimulating factorproducing breast cancer. Jpn Surg Assoc. 2019;8:1073-8.

12 Shimazaki A, Kono H, Okido M, Motoshita J, Fukami Y. A case of G-CSF-producing metaplastic breast cancer with chondroid differentiation. Jpn Surg Assoc. 2019;80:2148-52.

13 Asano S, Urabe A, Okabe T, Sato N, Kondo Y. Demonstration of granulopoietic factor (s) in the plasma of nude mice transplanted with a human lung cancer and in the tumor tissue. Blood. 1977;49:845-52. 